\title{
Monitoring the community use of antibiotics in Italy within the National Action Plan on Antimicrobial Resistance
}

\author{
Agnese Cangini ${ }^{1}$, Filomena Fortinguerra ${ }^{1}$, Aurora Di Filippo ${ }^{1}$, Andrea Pierantozzi ${ }^{1}$, \\ Roberto Da $\mathrm{Cas}^{2}$, Federico Villa ${ }^{3}$, Francesco Trotta ${ }^{1}$, MariaLuisa Moro ${ }^{4}$, and Carlo \\ Gagliotti $^{4}$ \\ ${ }^{1}$ Agenzia Italiana del Farmaco \\ ${ }^{2}$ National Institute of Health \\ ${ }^{3}$ Università del Piemonte Orientale Amedeo Avogadro Biblioteca del DIGSPES \\ ${ }^{4}$ Agenzia sanitaria e sociale regionale Regione Emilia-Romagna
}

April 28, 2020

\begin{abstract}
Background: In Italy both the consumption of antibiotics and the prevalence of bacterial resistance are higher than in other European countries. In 2017, the first National Action Plan on Antimicrobial Resistance (PNCAR) was adopted in Italy. In response to the PNCAR two National Reports on Antibiotics' use in the human setting have been published. The article's aim is to describe the pattern of antibiotics consumption in the community setting in Italy from 2013 to 2018 . Methods: In order to analyse the consumption for reimbursed antibiotics dispensed by community pharmacies different data sources were used. Consumption was measured in terms of Defined Daily Dose (DDD), prescriptions or prevalence of use. Results: In 2018, the consumption of antibiotics in Italy amounted to 16.1 DDD per 1,000 inhabitants per day. The rates of consumption by geographical area were: 12.7 DDD in the North, 16.9 in the Centre and 20.4 in the South. The use was greater in the extreme age groups than in the population aged from 20 to 64 years. The consumption was higher in winter season with high peaks in the incidence of flu syndromes. In the paediatric population, a utilization rate of 1,010 prescriptions per 1,000 children, with a prevalence of use of $40.8 \%$, was found. Conclusion: The study provides useful information on geographical variability of antibiotics' use in Italy to guide decision makers in the introduction of tailored interventions, as suggested by PNCAR, aimed at promoting a more rational use of antibiotics for humans and reducing antimicrobial resistance.
\end{abstract}

Corresponding author contact information: Agnese Cangini, Via del Tritone, 181-00187, Rome, Italy, a.cangini@aifa.gov.it

Principal Investigator statement: This manuscript is not a report on primary research performed with human subjects/patients; thus, there is no Principal Investigator for this paper.

\section{What is already known about this subject:}

- Antimicrobial resistance (AMR), which is considered a serious threat to public health worldwide, is correlated to the use of antibiotics.

- Antimicrobial stewardship programs need to be adapted to specific settings taking into account consumption patterns and prescription determinants. The assessment of geographical variability, patient characteristics and the possibility of linking prescriptions to clinical diagnoses enables intervention models to be adapted to the context making them more effective.

- In Italy both the community consumption of antibiotics and the prevalence of bacterial resistance are higher than in other European countries. 


\section{What this study adds}

- This study provides a model of analysis and presentation of antibiotic consumption data that can be replicated in other countries: different information sources and indicators are used (for example, prescriptions and prevalence of use are used for children); there is a strong focus on the informative value of data with disaggregation based on geographic areas and type of patients; information on diagnoses from a sentinel network of general practitioners is also provided; the seasonality of prescriptions is shown in parallel with the trend of flu syndromes.

- The analysis and presentation of these data (partly already used in national reports) is not only a surveillance activity but also acts as an implementation tool within the National Action Plan on Antimicrobial Resistance (PNCAR, 2017-2020) to allow the comparison between regions and promote the improvement actions already adopted in those settings that have better prescriptive profiles.

- This study fills an information gap on Italy's consumption and prescribing patterns which are presented in aggregate form in European reports, not highlighting the profound differences between areas both in terms of quantity and type of antibiotics used. In addition, the articles published so far are often in Italian and concern only some regions of the country.

\section{Hosted file}

paper_antibiotics_15042020.docx available at https://authorea.com/users/314051/articles/444445monitoring-the-community-use-of-antibiotics-in-italy-within-the-national-action-plan-on-antimicrobialresistance

\section{Hosted file}

Tables. docx available at https://authorea. com/users/314051/articles/444445-monitoring-the-communityuse-of-antibiotics-in-italy-within-the-national-action-plan-on-antimicrobial-resistance

\section{Hosted file}

Figure 1.docx available at https://authorea.com/users/314051/articles/444445-monitoring-thecommunity-use-of-antibiotics-in-italy-within-the-national-action-plan-on-antimicrobial-resistance

\section{Hosted file}

Figure 2.docx available at https://authorea.com/users/314051/articles/444445-monitoring-thecommunity-use-of-antibiotics-in-italy-within-the-national-action-plan-on-antimicrobial-resistance

\section{Hosted file}

Figure 3.docx available at https://authorea.com/users/314051/articles/444445-monitoring-thecommunity-use-of-antibiotics-in-italy-within-the-national-action-plan-on-antimicrobial-resistance

\section{Hosted file}

Figure 4.docx available at https://authorea.com/users/314051/articles/444445-monitoring-thecommunity-use-of-antibiotics-in-italy-within-the-national-action-plan-on-antimicrobial-resistance 